\title{
Salt profile and content in foods prepared in restaurants and bakeries: Analysis of the 2 main urban centers in Cape Verde
}

Edna Duarte Lopes ( $\nabla$ edna.d.lopes@insp.gov.cv )

National Institute of Public Health, Cape Verde

Júlio Monteiro Rodrigues

National Institute of Public Health, Cape Verde

Alzerina Maria Rocha Monteiro

Praia Health Precinct

Janice Soares

National Institute of Public Health, Cape Verde

Irina Spencer

National Directorate of Health

Maria da Luz Lima

National Institute of Public Health, Cape Verde

Ailton Luís Lopes Ribeiro

National Institute of Public Health, Cape Verde

\section{Research Article}

Keywords: salt $(\mathrm{NaCl})$ profile, salt $(\mathrm{NaCl})$ content, restaurants, bakeries

Posted Date: January 28th, 2022

DOI: https://doi.org/10.21203/rs.3.rs-1243524/v1

License: (c) (i) This work is licensed under a Creative Commons Attribution 4.0 International License. Read Full License 


\section{Abstract \\ Background}

The excessive intake of sodium from salt is associated with the risk of cardiovascular diseases. According to the Noncommunicable Diseases Survey (DNS, N/P), more than $35 \%$ of the Cape Verdean population is considered hypertensive. There are no data on the salt content of foods prepared by restaurants and bakeries in Cape Verde.

\section{Methods}

This was a cross-sectional study with a qualitative-quantitative approach conducted in bakeries and restaurants in the cities of Praia and Mindelo in Cape Verde. A total of 155 questionnaires were administered, and 152 food samples were collected for salt content analysis. The salt content $(\mathrm{g} / 100 \mathrm{~g})$ was determined by evaluating chlorides through titration by the Mohr method. The presence of iodine in the salt was evaluated by a rapid salt iodization test (lodized Salt Field Test Kit). Descriptive statistics were used to analyze the data. The salt content in the foods from the establishments in the 2 cities was compared by the chi-square test.

\section{Results}

Most restaurants and bakeries use iodized salt (97\%) of national origin (81\%), from the islands of Sal $(45.6 \%)$ and Maio $(20.9 \%)$. A total of $83.3 \%$ of the bakery managers reported following a standard that regulates the amount of salt to be used in bread preparation; $12 \%$ of restaurant managers reported following similar standards. Approximately $63.3 \%$ of the bread samples had salt contents greater than $1.4 \mathrm{~g} / 100 \mathrm{~g}$. The mean salt content recorded in meals was $1.3 \pm 0.5 \mathrm{~g} / 100 \mathrm{~g}$ in Praia and $1.4 \pm 0.5 \mathrm{~g} / 100$ $\mathrm{g}$ in Mindelo. Approximately $41 \%$ of the meals collected from restaurants in Praia and $55 \%$ in Mindelo had a salt content between $5.20 \mathrm{~g}$ and $10.83 \mathrm{~g}$.

\section{Conclusions}

Restaurants and bakeries in the cities of Praia and Mindelo use salt in a nonstandardized manner, requiring special attention from all stakeholders. The results of this study may contribute to the redesign of salt intake reduction strategies in Cape Verde.

\section{Background}

Noncommunicable diseases (NCDs) are responsible for the death of 41 million people annually, equivalent to $71 \%$ of all deaths worldwide, with cardiovascular diseases being the main cause (17.9 
million) (1). In turn, hypertension is the leading cause of cardiovascular disease and premature death worldwide (1).

In Cape Verde, due to changes in the demographic, epidemiological and nutritional profiles of the Cape Verdean population, chronic NCDs are the leading cause of mortality in the country (MS, N/P). According to preliminary data from the 2019 Survey on Noncommunicable Diseases and Associated Risk Factors (IDNT II, acronym in Portuguese), $30.8 \%$ of the Cape Verdean population is hypertensive.

According to the World Health Organization (WHO), high blood pressure is responsible for at least $45 \%$ of deaths from heart disease and $51 \%$ of deaths from stroke (1). The worldwide prevalence of high blood pressure (systolic and/or diastolic blood pressure $\geq 140 / 90 \mathrm{mmHg}$ ) in adults (age $\geq 18$ years) is estimated at $22 \%(2,3)$. Data from the 2019 IDNT II indicate that cardiovascular diseases and cancer are leading causes of deaths in Cape Verde, highlighting poor eating habits among the most common risk factors (MS, N/P).

When poor eating habits are identified as one of the risk factors for circulatory system diseases and cancer, among other conditions, substances such as salt (sodium chloride) and other additives such as preservatives used in canned foods, meat, fish, etc., are often mentioned. However, the identity and nature of these substances, as well as their effects on the body, are rarely explained (4). In developed countries, up to three-quarters of the total salt intake comes from foods consumed outside the home and from processed foods, in contrast, the salt added to food, both at the table and during home preparation, generally represents a lower proportion of the total sodium intake $(5,6)$.

Sodium is an essential nutrient necessary for the normal functioning of cells. Its excessive intake is associated with adverse health conditions, particularly hypertension, which in turn is considered one of the main risk factors for some chronic diseases with high morbidity and mortality worldwide (7-9). According to Nascimento et al. (10), sodium ( $\mathrm{Na}$ ) intake comes mainly from table salt, salt-based foods and industrialized products. Complications are related to sodium intake in amounts above that recommended by the WHO of a maximum of $2 \mathrm{~g} /$ day (8), considering all its forms of presentation.

Although the 2019 IDNT II (MS, N/P) indicates that close to one-third of the Cape Verdean population is hypertensive, there are no data on the salt profile and content of foods prepared by restaurants and bakeries in Cape Verde. Thus, the main objective of this study was to evaluate the profile and content of salt in foods prepared in restaurants and bakeries in the cities of Praia and Mindelo in Cape Verde.

\section{Methods}

\section{Study design and population}

This was an observational, cross-sectional study with a qualitative-quantitative approach conducted in restaurants and bakeries in the cities of Praia and Mindelo. These cities have the largest populations in the country (11). All restaurants and bakeries in the 2 cities, based on georeferencing data provided by the 
Independent Health Regulatory Entity (ERIS, acronym in Portuguese), Municipal Councils and the General Directorate of Tourism, were eligible for the study, and all representatives who agreed to participate did so voluntarily. In cases where the georeferenced establishment was already closed, the data were collected from the nearest unreferenced establishment. Written informed consent was provided by the representative of each establishment prior to data collection.

\section{Participant characteristics}

A total of 155 managers of restaurants and bakeries in the cities of Praia and Mindelo participated in the study, most of whom (61.4\%) were female. Most subjects were aged $25-44$ years (58.2\%). The mean age of the respondents was $32.41 \pm 8.41$ years. Regarding education level, $48.1 \%$ completed secondary education, $28.5 \%$ completed primary education, $15.2 \%$ completed undergraduate education, $2.5 \%$ completed vocational training, $1.9 \%$ had a master's degree, and $1.3 \%$ were illiterate.

\section{Data collection}

\section{Questionnaires and food samples}

A protocol cover sheet containing the identification data of the establishment and 2 adapted self-report questionnaires (Appendix I and II) (12) were applied to record observations on the origin, transport, storage and use of salt used in the establishments under study.

The data were collected by 11 investigators under the supervision of 2 supervisors; the investigators were distributed between the cities of Praia ( 6 investigators; 1 supervisor) and Mindelo ( 5 investigators; 1 supervisor). The investigators underwent 1 week of training on techniques for questionnaire application and techniques for collecting, packaging and transporting food samples, on the ethical issues of the research, and on the analysis and interpretation of salt iodization data based on the instructions of the lodized Salt Field Test Kit.

The food samples were collected in dry sterile polyethylene bags to avoid any possible contamination and were transported in thermal bags containing cold packs in accordance with the best practices for food transport (13). In the laboratory, the samples were stored at $-20^{\circ} \mathrm{C}$ until analysis.

\section{Rapid salt iodization test}

In each establishment, a small amount of salt (approximately one teaspoon) was collected on a white paper sheet, to which 1-2 drops of the test solution was added (14). Using a color table provided in the test kit, the result was recorded immediately under good lighting. For cases where no color was observed after 1 minute (suspicion of alkalinity in the salt sample), 5 drops of verification solution was added to a new salt sample, and 2 drops of the test solution was added to the sample (14). Last, using the color table, the result was recorded and transcribed to the questionnaire sheet.

\section{Laboratory analysis}




\section{Sample preparation}

Bread samples were ground in a blender immediately after their removal from the freezer, and the portion needed for salt content analysis was separated and set aside.

Samples of meals were slowly thawed, i.e., kept in a refrigerator at $\sim 4^{\circ} \mathrm{C}$ for a period of 24 hours. Then, the samples were homogenized in a blender, and the necessary portion was removed for analysis.

\section{Analysis of sodium chloride content}

After sample homogenization, approximately $5 \mathrm{~g}$ of Portuguese bread/wheat bread and $10 \mathrm{~g}$ of meals were weighed in duplicate on an analytical inside $250-\mathrm{ml}$ cups. Then, $100 \mathrm{ml}$ of warm distilled water (50$\left.55^{\circ} \mathrm{C}\right)$ and $100 \mathrm{ml}$ of boiling distilled water $\left(\sim 100^{\circ} \mathrm{C}\right)$ were added to the cups containing bread and meal samples, respectively (15).

The solution was vigorously homogenized ( $30 \mathrm{~s}$ ) twice at an interval of 1 minute. After the solution had cooled to room temperature, the $\mathrm{pH}$ was adjusted to 6.5-10.0, and the solution was filtered through sterile gauze. Next, $15 \mathrm{ml}$ of the filtered solution was transferred to a 250-ml Erlenmeyer flask, and $1.5 \mathrm{ml}$ of 0.1 $\mathrm{M}$ potassium chromate indicator $\left(\mathrm{K}_{2} \mathrm{CrO}_{4}\right)$ was added (13). The solution was then titrated with $0.1 \mathrm{M}$ silver nitrate $\left(\mathrm{AgNO}_{3}\right)$ until the first appearance of a brownish red color; the process was continued for another $30 \mathrm{~s}$, and the volume of titrant used was recorded (13).

\section{Calculations and formulas}

The sodium chloride content in each replicate sample was calculated, and the mean, median and standard deviation were calculated.

Formulas:

- Salt content in $\mathrm{g} / 100 \mathrm{~g}$ of sample:
A. $\mathrm{mNaCl}=\mathrm{C}\left(\mathrm{AgNO}_{3}\right) \times \mathrm{V}($ spent $) \times \mathrm{MMNaCl}$
B. $\mathrm{mNaCl}---15 \mathrm{ml}$
$\mathrm{X}-\mathbf{-}-100 \mathrm{ml}$
C. $\mathrm{mNaCl}-5 \mathrm{~g}[1]$
D. $\mathrm{mNaCl}-10 \mathrm{~g}[2]$
$\mathrm{X}-\mathrm{-}-100 \mathrm{~g}$
$\mathrm{X}$ - $100 \mathrm{~g}$

\section{Statistical analysis}

The data were analyzed using the Statistical Package for the Social Sciences (SPSS, v. 26). The data were described using absolute and relative frequencies, and the chi-square test was used to compare the salt content in foods prepared by the establishments in Praia and Mindelo. 
[1] Amount of bread/analysis.

[2] Amount of meal/analysis.

\section{Results}

Salt used in restaurants

A total of 125 restaurants were evaluated. Regarding the origin of the salt used during food preparation in the restaurants, $79 \%$ of restaurants used salt of national origin, $13.7 \%$ used salt of international origin, $4 \%$ used salt of both origins, and 3.2\% used salt of an unknown origin.

Of the restaurants in which the salt used in food preparation was of national origin, $62.6 \%$ used salt from the island of Sal, and $25.3 \%$ used salt from the island of Maio; for $12.1 \%$, the island of origin was unknown. Notably, the island of Santiago does not produce salt.

Of the restaurants in which the salt used in food preparation was of international origin, $95 \%$ used salt from Portugal, and $5 \%$ used salt from France.

Regarding the means used to transport salt, $61.1 \%$ of restaurants used a car, $18.2 \%$ used a car and boat, $7.1 \%$ used a car and plane, and $13.5 \%$ did not use any means of transport.

Most restaurants (58.4\%) did not have a specific location for salt storage. The salt was stored in its original packaging (91.9\%), protected from light (38.7\%), exposed to heat in a nonventilated area (19.4\%), stored in the presence of chemicals (9.7\%), and exposed to moisture (6.5\%).

Other forms of salt storage indicated by the respondents were in plastic buckets (30\%), together with other nonperishable foods (25\%), in flasks (15\%), in stainless steel containers (10\%), in plastic bowls (10\%), inside a kitchen cabinet (5\%) and in a bag inside a box (5\%).

Among the restaurants that did not have a specific location for salt storage, in $79.6 \%$, the salt was stored in the kitchen; in $12.2 \%$, the salt was stored in the pantry; in $4.1 \%$, the salt was stored on a kitchen shelf; and in $2 \%$, the salt was stored on a shelf or near the stove.

Regarding the lighting where the salt was stored, the location was well lit in $30.6 \%$ and lit in $26.5 \%$ of restaurants, received natural light in $22.4 \%$, low light in $12.2 \%$, and no light in $4.1 \%$ of restaurants, and was exposed to light and heat in $2 \%$ of restaurants.

The salt storage location was ventilated in $44.7 \%$ of the restaurants, well ventilated in $23.4 \%$, poorly ventilated in $12.8 \%$, ventilated and exposed to heat in $6.4 \%$, not ventilated in $4.3 \%$, exposed to heat in $4.3 \%$ and exposed to natural ventilation in $2.1 \%$.

In $29.2 \%$ of the restaurants, the salt was stored in its own packaging; in $37.5 \%$, the salt was stored in plastic jars; in $12.5 \%$, the salt was stored in a container with a lid; in $6.3 \%$, the salt was stored in plastic bags; in $6.3 \%$, the salt was stored in jars; in $4.2 \%$, the salt was stored in a random container; and in $4.2 \%$, 
the salt was stored in glass jars. In $82.1 \%$ of the restaurants, the salt was stored together with other products.

Most restaurants (83.3\%) used a utensil for handling salt: spoon (69.8\%), cup (4\%), ladle (4\%), stainless steel scoop $(1.6 \%)$, spoon and jar (1.6\%), milk pitcher $(0.8 \%)$, jar $(0.8 \%)$ and wooden spoon $(0.8 \%)$.

Salt used in bakeries

A total of 30 bakeries were evaluated. Most of the salt used in the preparation of bread was of national origin, with $55.6 \%$ of bakeries using salt from the island of Sal and $37 \%$ using salt from the island of Maio; $7.4 \%$ reported not knowing the provenance.

The car was the most commonly used means for transporting salt (76.7\%), followed by boat and car (20.0\%) and plane and car (3.3\%). Most bakeries purchased salt locally (76.7\%) and stored it in a specific location (80\%). Of these, $78.3 \%$ stored the salt in its original container, $47.8 \%$ stored the salt protected from light, $30.4 \%$ stored the salt in a location exposed to heat, $4.3 \%$ stored the salt in a nonventilated area, and $4.3 \%$ stored the salt in the presence of chemicals.

Of the 6 bakeries that did not have a specific location for salt storage, 50\% stored it in the pantry, 33.3\% stored it in the production area, and $16.7 \%$ stored it in a location with other products. In $66.7 \%$ of the bakeries, the salt was stored away from light; in $50 \%$, the salt was stored in its own container; in $33.3 \%$; the salt was exposed to heat; and in $16.7 \%$; the salt was stored in an unventilated location.

A total of $96.4 \%$ of the bakeries used a utensil to handle the salt: cup (25.9\%), ladle (25.9\%), stainless steel scoop (14.8\%), bowl (7.4\%), shaker (7.4\%), and either a spoon, scale plate, spatula, cake pan or jar (3.7\% each).

Profile of the salt used in restaurants

Only $12 \%$ of the restaurant managers stated that they followed standard guidelines for the amount of salt to be used in food preparation.

Most (67.2\%) restaurant managers believe that there are differences between different types of salt, whereas $30.4 \%$ think there are no differences and $2.4 \%$ do not know. Of those who reported the existence of differences between the types of salt, $59.5 \%$ referred to the quality, with emphasis on the presence of iodine (30\%).

Table 1 shows the proportion of salt per meal used by restaurants in Praia and Mindelo. In both the soup and the main dish, most establishments used less than $1 \mathrm{~g}$ of salt. 
Table 1

Amount of salt/meal used in restaurants

\begin{tabular}{|lllll|}
\hline Salt & \multicolumn{3}{l}{ Restaurants } & \\
\cline { 2 - 5 } & \multicolumn{2}{l}{ Soup } & \multicolumn{3}{l|}{ Main dish } \\
\cline { 2 - 5 } & $\mathbf{n}$ & $\%$ & $\mathbf{n}$ & $\%$ \\
\hline$<1 \mathrm{~g}$ & 75 & 59.5 & 65 & 51.6 \\
\hline 1 to $2 \mathrm{~g}$ & 25 & 19.8 & 40 & 31.7 \\
\hline 2 to 4 g & 7 & 5.6 & 14 & 11.1 \\
\hline 4 to 6 g & 1 & 0.8 & 2 & 1.6 \\
\hline$>6$ g & - & - & 5 & 4 \\
\hline Does not cook & 17 & 13.5 & - & - \\
\hline Does not know & 1 & 0.8 & - & - \\
\hline Total & 126 & 100 & 126 & 100 \\
\hline
\end{tabular}

Regarding the daily dose of salt recommended by the $\mathrm{WHO}, 48 \%$ of respondents were unaware of the existence of a WHO recommendation on the amount of salt that should be consumed daily per person; $18.4 \%$ were aware of such a recommendation.

Only $37.3 \%$ of the respondents knew the relationship between salt and sodium.

Profile of the salt used in bakeries

Regarding the existence of a standard that regulates the amount of salt to be used in the preparation of bread, $83.3 \%$ of the bakeries reported that they followed a standard; for the remaining $16.7 \%$, there was no compliance with any standard.

lodized salt was the most used salt type (90\%), followed by sea salt, fleur de sel and others, with $3.3 \%$ each.

Most respondents (69\%) stated that there were differences between types of salt; the remaining $31 \%$ responded that no differences exist between different types. The most reported differences between the types of salt were quality ( $41.2 \%)$, followed by texture (17.6\%). Among the respondents, $11.8 \%$ considered iodized salt the best, and differences were reported in terms of appearance, taste/aroma, presence of iodine, importance for health and salt content in the recipe (5.9\% each).

The amount of salt per $\mathrm{kg}$ of dough was greater than $14 \mathrm{~g} / \mathrm{kg}$ in 3 bakeries, and in 2 bakeries, the amount of salt was greater than $6 \mathrm{~g}$ per loaf (Table 2). 
Table 2

Amount of salt per kg of dough and per

loaf

\begin{tabular}{|lllll|}
\hline Salt & \multicolumn{3}{l|}{ kg of dough } & \multicolumn{2}{l|}{ Loaf } \\
\cline { 2 - 6 } & $\mathbf{n}$ & $\%$ & $\mathbf{n}$ & $\%$ \\
\hline$<1 \mathrm{~g}$ & 4 & 14.3 & 21 & 75 \\
\hline 1 to $2 \mathrm{~g}$ & 1 & 3.6 & 5 & 17.9 \\
\hline 2 to $4 \mathrm{~g}$ & 1 & 3.6 & - & - \\
\hline 4 to $6 \mathrm{~g}$ & 1 & 3.6 & - & - \\
\hline$>6 \mathrm{~g}$ & 21 & 75 & 2 & 7.1 \\
\hline
\end{tabular}

The majority of the bakery managers (96.7\%) believe that salt has an impact on the health of all individuals. Only $3.3 \%$ considered that it has an impact only on the health of individuals with some disease.

Most respondents (66.7\%) were unaware of the daily dose of salt recommended by the WHO $(5 \mathrm{~g} / \mathrm{day})$; $6.7 \%$ were aware of such a recommendation.

Regarding the relationship between salt and sodium, $36.7 \%$ of the respondents answered that salt contains sodium; 53.3\% did not know the relationship between the 2 .

Laboratory results

A total of 155 food samples were collected, and 152 were analyzed, 30 of which were bread (Portuguese/wheat bread) and 122 of which were meals ready for consumption. Of these, 75 were collected in the city of Praia (16 bread samples and 59 meal samples), and 77 were collected in the city of Mindelo (14 bread samples and 63 meal samples).

Of the bread samples analyzed, $63.3 \%$ had salt contents above the limit recommended by the Portuguese standard (Decree Law no. 75/2009, of 12 August). This standard defines a maximum permitted salt content, i.e., $1.4 \mathrm{~g}$ per $100 \mathrm{~g}$ of baked bread (or $0.55 \mathrm{~g}$ of sodium per $100 \mathrm{~g}$ of bread). Of the samples with salt contents equal to or greater than $1.4 \mathrm{~g} / 100 \mathrm{~g}, 57.8 \%(n=11)$ were collected in the city of Mindelo, and $42.2 \%(n=8)$ were collected in the city of Praia.

Approximately $41 \%$ of the meal samples collected in Praia and $55 \%$ in Mindelo had a $\mathrm{NaCl}$ content higher than the maximum daily intake recommended by the WHO $(5 \mathrm{~g} /$ day of $\mathrm{NaCl})$. All of these samples had a common component (meat) that underwent some traditional preserving process (use of salt as a preservative). 
In the present study, the amount of Na varied between $0.78 \mathrm{~g}$ and $4.33 \mathrm{~g}$ per meal, with a median of $1.9 \mathrm{~g}$, indicating a high $\mathrm{Na}$ content based on the recommended daily intake of less than $2 \mathrm{~g}$ of Na established by WHO (8).

Bakeries and restaurants in Mindelo used a mean of $1.5 \pm 0.3 \mathrm{~g}$ of salt $/ 100 \mathrm{~g}$ of bread and $1.4 \pm 0.5 \mathrm{~g}$ of salt/100 g of meal. In Praia, the mean salt content in bread was $1.35 \pm 0.3 \mathrm{~g} / 100 \mathrm{~g}$, and that in meals was $1.3 \pm 0.5 \mathrm{~g} / 100 \mathrm{~g}$. There were no significant differences between Praia and Mindelo regarding the salt content used in the bakeries $(p=0.419)$ or in the restaurants $(p=0.631)$.

Most of the salt samples collected (97\%) contained iodine.

\section{Discussion}

In this study, most salt samples contained iodine (97\%), a result that is in accordance with the WHO recommendations ( $\geq 90 \%$ ) established to eliminate iodine deficiency disorders (14).

The high percentage (97\%) of use of iodized salt by the restaurants and bakeries may be due to the efforts of the Cape Verdean government to stimulate improvements in the iodine status in recent years. This rate is consistent with that found in a study conducted in Nigeria (95\%) and is higher than that found in studies in Ghana (75.6\%) and Senegal (10\%) on the salt iodine content in the household diet and associated factors $(16,17)$.

Most restaurants did not have a specific location for storing salt. It was stored in its own packaging, protected from light, exposed to heat, stored in a nonventilated place, stored in the presence of chemicals, and exposed to moisture. Several studies have shown that storing iodized salt in a dry or cold place protected from sunlight preserves its composition $(14,18-20)$.

Bread is one of the most consumed foods in the world, accounting for an average of $30 \%$ of daily salt intake $(2,3)$. It contributes a significant percentage of salt to the diet of the Cape Verdean population. Of the bread samples analyzed, $63.3 \%$ had a salt content greater than the limit recommended by the Portuguese standard, which is $1.4 \mathrm{~g} / 100 \mathrm{~g}$ of bread or $0.55 \mathrm{~g}$ of sodium/100 $\mathrm{g}$ of bread (21).

Of the samples with salt contents greater than or equal to $1.4 \mathrm{~g} / 100 \mathrm{~g}, 57.8 \%(\mathrm{n}=11)$ were collected in the city of Mindelo, and $42.2 \%(n=8)$ were collected in the city of Praia (21). Similar results were found in a study on the evaluation of salt content in bread regularly consumed in the Eastern Mediterranean region $(21,22)$.

The results of the present study indicate that the salt content in meals prepared in restaurants in Cape Verde is high $(5.2=\nabla \mathrm{g} / \mathrm{meal})$ based on the WHO recommendation (8).

A higher salt content was observed in meals that contained meat, french fries, chorizo or shellfish. This may be due to some traditional preservation processes (use of salt as a preservative) (23). Conversely, the samples consisting essentially of salad had low salt contents (10). 
Approximately $41 \%$ of the meal samples collected in the restaurants in Praia and $55 \%$ in Mindelo had a $\mathrm{NaCl}$ content between $5.20 \mathrm{~g}$ and $10.83 \mathrm{~g}$ per meal, with a median of $4.8 \mathrm{~g}$, suggesting a much higher daily $\mathrm{NaCl}$ intake than the maximum limit $(<5 \mathrm{~g} /$ day) recommended by the WHO $(1,8)$. An intake of less than $5 \mathrm{~g}$ of salt per day in adults helps to reduce blood pressure and the risk of cardiovascular disease, stroke and heart attack (8).

In the present study, the amount of $\mathrm{Na}$ ranged from $780 \mathrm{mg}$ to $4,330 \mathrm{mg} / \mathrm{meal}$, with a median of 1,900 $\mathrm{mg} /$ meal, which exceeds not only the recommendation for a meal $(15,24,25)$ but also the WHO daily recommendation, which establishes a maximum intake of 2,000 $\mathrm{mg}$ of $\mathrm{Na} /$ day (8).

The results should be interpreted considering that the data were collected only in the 2 main population centers. Thus, it is possible that there are other bakeries and restaurants that were not taken into account.

\section{Conclusions}

The hypothesis that the restaurants and bakeries in the cities of Praia and Mindelo are unaware of the origin, mean of transport and storage of the salt they use was refuted. It was found that most restaurant and bakery managers know the origin and the means of transport of the salt they use and stored it in appropriate places and under appropriate conditions.

The hypothesis that the restaurants and bakeries in the cities of Praia and Mindelo use salt in a nonstandardized manner was confirmed. There was a lack of standards for salt use in all establishments studied. This was in addition to the fact that the managers were unaware of the international standards for salt use.

The hypothesis that the salt used by restaurants and bakeries in the cities of Praia and Mindelo contains sodium chloride above international standards was also confirmed. It was found that the salt used by most restaurants and bakeries in both cities contained $\mathrm{Na}$ and $\mathrm{NaCl}$ in quantities much higher than those recommended internationally.

However, most of the salt used in bakeries and restaurants contained iodine.

The results of this study may contribute to the redesign of salt intake reduction strategies in Cape Verde. It is imperative and urgent that national legislation regulate the unit weight of bread and the amount of salt that ready-to-eat foods, including bread, should contain.

\section{Abbreviations}

$\mathrm{AgNO}_{3}$

Silver nitrate

CNCDs

Chronic noncommunicable diseases 
DNS

National Directorate of Health

NCDs

Noncommunicable diseases

IDNT

Noncommunicable Disease Survey

ERIS

Independent Health Regulatory Authority

$\mathrm{K}_{2} \mathrm{CrO}_{4}$

Potassium chromate

$\mathrm{mNaCl}$

Sodium chloride mass

$\mathrm{MMNaCl}$

Sodium chloride molar mass

$\mathrm{Na}$

Sodium

$\mathrm{NaCl}$

Sodium chloride

SPSS

Statistical Package for the Social Sciences

WHO

World Health Organization

\section{Declarations}

\section{Ethics approval and consent to participate}

This study was approved by the National Committee on Ethics in Health Research (deliberation no. 33/2019, 31 May). All participants signed an informed consent form, which was filed under confidentiality at the National Institute of Public Health of Cape Verde. Written informed consent for participation was obtained from managers of restaurants and bakeries and their privacy and confidentiality were maintained. All personal identifiers were excluded, and data was kept confidential and used for the proposed study only.

\section{Guideline statement}

Resolution No. 33/2019

1. It was submitted, under the terms of article 9 of Decree-Law No. 26/2007, of 30 July, for the purposes of the National Committee on Ethics in Health Research (CNEPS, acronym in Portuguese) opinion in order to authorize the realization of the Project entitled " Salt profile and content in foods prepared in 
restaurants and bakeries: Analysis of the 2 main urban centers in Cape Verde", presented by the National Institute of Public Health, INSP, with Dr Júlio Monteiro Rodrigues as the main researcher, Executive Director of the aforementioned Institute, which has a partnership with the Institute of Hygiene and Tropical Medicine, Lisbon, Portugal.

2. The research project team is comprised not only of technicians responsible for the INSP, but also of the Coordinator of the National Nutrition Program, the National Directorate of Health and technicians from the Praia Health Precinct, among others.

3. This is an observational, cross-sectional study with quali-quantitative approaches.

4. The study will take place in the cities of Praia and Mindelo and will cover a representative sample of restaurants and bakeries, based on georeferencing, provided by the General Directorate of Tourism and/or the National Statistics Institute, INE.

5. Only duly registered restaurants and bakeries whose representatives accept to participate in the study will be considered.

6. As supporting documents, were presented, (i) the Letter addressed to CNEPS, (ii) the Research Project, (iii) the Schedule, (iv) the Indicative Budget, (v) the Information Sheets, (vi) the Terms of Free and Informed Consent, (vii) the Questionnaires to be applied and, (viii) the CV of the principal investigator?

7. CNEPS performed the document analysis of the research project during its 92nd Ordinary Meeting, held on April 25, 2019, and the project was pending additional information (see deliberation 28/2019).

8. On May 15, 2019, the research project with the corrections was submitted for reconsideration by the CNEPS.

9. CNEPS reassessed the research project during its 92nd Ordinary Meeting, held on May 30, 2019, having found that the aspects highlighted in the aforementioned determination were remedied, therefore, pursuant to article 11 of Decree-Law no. 26/2007, of 30 July, it decided to approve it.

\section{Consent for publication}

Not applicable

\section{Availability of data and materials}

All datasets on which the conclusions of the manuscript rely are presented in the main paper.

\section{Competing interests}

No funding was obtained for this study. The authors declare that they have no financial and/or personal conflicts of interest in the design and implementation of this study. 


\section{Funding}

The study was supported by the National Institute of Public Health through the state budget.

\section{Authors' contributions}

- JR and IS participated in the conception and design of the study.

- AR participated in the conception and design of the study, interpreted the data, carried out the experiments, prepared the investigation report, and drafted the article.

- EL participated in the conception and design of the study, prepared and supervised the data collection, supervised the statistical analysis, interpreted the data, prepared the investigation report, reviewed the manuscript critically, and drafted the article.

- $A M$ and AR trained the inquirers and prepared and supervised the data collection.

- JS performed the statistical analysis, interpreted the data, and prepared the investigation report.

- All authors read and approved the final manuscript and agreed with the decision to publish this study.

\section{Acknowledgments}

The authors would like to thank everyone who contributed to this study.

\section{References}

1. World Health Organization. Noncommunicable diseases. 2021. Available from: https://www.who.int/news-room/fact-sheets/detail/noncommunicable-diseases.

2. Mills KT, Stefanescu A, He J. The global epidemiology of hypertension. Nat Rev Nephrol. 2020;16(4):223-37.

3. World Health Organization. Hypertension 2021. Available from: https://www.who.int/newsroom/fact-sheets/detail/hypertension.

4. Molognoni L. Interações de conservantes no processamento de carnes: Formação de compostos carcinogênicos, métodos de controle e agentes inibitórios: Universidade Federal De Santa Catarina; 2019.

5. Coelho PFdC. A prática social do consumo insustentável de alimentos para viagem no Brasil e Alemanha. 2021.

6. Ruiz AMP, Lima MG, Medina LPB, Pinto RL, Barros MBA, Filho AAB. Can Meals Outside Homes Impact Sodium Intake? Current developments in nutrition. 2020;4(6):nzaa091.

7. National Academies of Sciences E, Medicine, Health, Medicine D, Food, Nutrition B, et al. The National Academies Collection: Reports funded by National Institutes of Health. In: Oria M, Harrison M, Stallings VA, editors. Dietary Reference Intakes for Sodium and Potassium. Washington (DC): 
National Academies Press (US) Copyright 2019 by the National Academy of Sciences. All rights reserved.; 2019.

8. World Health Organization. Salt reduction. 2020. Available from: https://www.who.int/newsroom/fact-sheets/detail/salt-reduction.

9. Organization WH. Guideline: sodium intake for adults and children2012. Available from: https://www.who.int/publications/i/item/9789241504836.

10. Nascimento RFd, Gavron AB, Bowles S, Chaves ES, Bortolozo EAFQ. Determinação dos teores de sódio e potássio em refeições servidas em um restaurante universitário da região sul do Brasil. Brazilian Journal of Food Technology. 2017;20.

11. Instituto Nacional de Estatística de Cabo Verde. ANUÁRIO ESTATíSTICO 20182020.

12. Viegas CACL. O sal na alimentação dos jovens: avaliação e perceção do sal das refeições. 2013.

13. Associação de restauração e similares de Portugal. Código de boas práticas para o transporte de alimentos. 2008.

14. World Health Organization. Assessment of iodine deficiency disorders and monitoring their elimination: a guide for programme managers. 2007.

15. Ward REaC. Traditional methods for mineral analysis. In: Analysis F, editor. SS Nielsen 4th ed. Springer, New York.2010.

16. Anteneh ZA, Engidayehu M, Abeje G. lodine content of dietary salt at household level and associated factors using iodometric titration methods in Dera District, Northwest Ethiopia. BMC nutrition. 2017;3:83-.

17. Obssie GF, Ketema K, Tekalegn Y. Availability of Adequately lodized Dietary Salt and Associated Factors in a Town of Southeast Ethiopia: A Community-Based Cross-Sectional Survey. J Nutr Metab. 2020;2020:1357192-.

18. Goris JM, Temple VJ, Zomerdijk N, Codling K. lodine status of children and knowledge, attitude, practice of iodised salt use in a remote community in Kerema district, Gulf province, Papua New Guinea. PLoS One. 2018;13(11):e0197647.

19. Mekonnen TC, Eshete S, Wasihun Y, Arefaynie M, Cherie N. Availability of adequately iodized salt at household level in Dessie and Combolcha Towns, South Wollo, Ethiopia. BMC public health. 2018;18(1):1-9.

20. Abebe Z, Gebeye E, Tariku A. Poor dietary diversity, wealth status and use of un-iodized salt are associated with goiter among school children: a cross-sectional study in Ethiopia. BMC Public Health. 2017;17(1):44.

21. Assembleia da República. Lei n. ${ }^{\circ} 75 / 2009$ de 12 de agosto Diário da República, 1. ${ }^{\text {a }}$ série, 2009 [5225 - 6]. Available from: https://dre.pt/pesquisa/-/search/493513/details/maximized.

22. Al Jawaldeh A, Al-Khamaiseh M. Assessment of salt concentration in bread commonly consumed in the Eastern Mediterranean Region. Eastern Mediterranean health journal = La revue de sante de la Mediterranee orientale = al-Majallah al-sihhiyah li-sharq al-mutawassit. 2018;24(1):18-24. 
23. Vidal VAS. Redução de sódio em carnes salgadas: efeitos da substituição parcial de cloreto de sódio por outros sais clorados. 2019.

24. Council NR. Recommended Dietary Allowances. 10th ed1989.

25. Ministério da Saúde do Brasil. Guia alimentar para a populacao Brasileira. 2 ed. Brasil2014. 156 p.

\section{Supplementary Files}

This is a list of supplementary files associated with this preprint. Click to download.

- Appendix.docx 